\title{
Spatial Distribution of Survey Controls and Effect on Accuracy of Geometric Geoid Models (Multi- quadratic and Bicubic) in FCT, Abuja
}

\author{
*Oluyori, P. D. and Eteje, S. O. \\ Department of Surveying and Geoinformatics \\ Nnamdi Azikiwe University, Awka, \\ Anambra State, Nigeria \\ *Corresponding Author: dareoluyori@gmail.com \\ DOI: $10.31364 / S C I R J / v 7 . i 5.2019 . P 0519650$ \\ http://dx.doi.org/10.31364/SCIRJ/v7.i5.2019.P0519650
}

\begin{abstract}
Spatially distributed studies may follow two broad approaches: points that are randomly located and points that are clustered or clumped together. They are discussed within a discipline described as geo-statistics. Geo-statistics is applied in order to interpolate geoid undulation $(N)$ and hence generate through a geoid model orthometric heights from scattered/random or closely/clustered located controls. Control points are coordinated points within a primary/secondary geodetic survey network. Kriging method was adopted to produce topographical maps of the both scattered and closely scenarios. Accuracy computed revealed that standard deviation $(\sigma)$ of multiquadratic and bicubic models in the study area are respectively $11 \mathrm{~cm}$ and $14 \mathrm{~cm}$ in lopsided control study area while over clustered distributed located controls are respectively $12 \mathrm{~cm}$ and $15 \mathrm{~cm}$. Standard deviation with the lowest values among the determined geometric geoid models is at all times preferable scattered/random than closely/clumped scenario. This implies that the multiquadratic models can be applied across the entire study area with high accuracy/reliability irrespective of spatial distribution of the points. Hence, the accuracy of the models are better when the total number of points distributed within the entire study area was used than when a limited number of points within a particular part of the study area was used.
\end{abstract}

Keywords: spatial, distribution, multiquadratic, bicubic, geometric, geoid, model, accuracy

\section{INTRODUCTION}

In accordance with Tobler's first law of geography introduced by Waldo R Tobler (1969), all geographic objects share certain similarities, but their similarity decreases with an increase in distance between these objects opined Longley et al. (2005). The need for homogeneous distribution of controls in geometric geoid modelling has been stressed by several researchers including Erol and Celik (2004), Kaloop et al (2008), among several others. However, circumstances in practical reality may make homogeneity impossible/infeasible (location of various classes of controls) and therefore the need to investigate the implication of such occurrences is desirable by computing accuracy/standard deviations $(\sigma)$. Geoid modelling by Nwilo (2013), Eteje et al (2018), Oluyori (2019), and others may be applied to modernization of heights to produce orthometric heights by reference to vertical datum when adopting Global Positioning System (GPS) technology. GPS technology produces three dimensional coordinates $(\mathrm{N}, \mathrm{E}, \mathrm{h})$ relative to earth ellipsoid. To obtain orthometric height $(\mathrm{H})$ of a point from GPS observations, a geoid undulation (N) of the point is needed. Eteje et al. (2018) and Oluyori (2019) gave the model for the transformation of the GPS ellipsoidal height $(\mathrm{h})$ to orthometric height $(\mathrm{H})$ if the geoid height is known as:

$$
H=h-N
$$

In applications requiring mapping, cadastral, engineering, etc., the above relationships, equation (1) is necessary and desirable. Vertical datum is referred to as geopotential reference frame capturing gravity, geoid undulation, orthometric height and deflection of the vertical while geometric reference frame is used to replace horizontal datum to include geocentric X, Y, Z; latitude, longitude and ellipsoid height (h) according to Hansar (2016). Nwilo (2013) as well as Oluyori (2019) can fit into modern categorization of height modernization. One very important factor to be stressed in accuracy determination in geometric geoid modelling according to Kaloop et al (2008) is the spatial distribution and number of controls available within study area. If observation points do not reliably represent the analyzed area or represent only its part, the resulting model will be burdened by significant errors, which will contribute to high prediction errors opined Cellmer (2014). Issues related to number of controls and spatial distribution may lead to loss of surface reality and hence suitability of surface and in fact Ning (2015) pointed to reduction of "internal precision" arising from increase to more observations with attendant costs.

The main goal of this study is to find out if the spatial arrangements of the location of the controls have an impact on the accuracy achieved on the geoid models within the study area by computing and comparing their standard deviation/accuracy. 


\section{Scope of Study}

This study is limited to comparison of the accuracy of geometric geoid models of Federal Capital Areas of Abuja as depicted in Figures 3 and 4 using orthometric heights of concentrated and widely separated controls within the study area. Two hours Relative GPS observations was used for data acquisition over primary and secondary controls.

\section{Study Area}

Federal Republic of Nigeria consists of 36 states and Federal Capital, the FCT, Abuja. Details of study are given in Oluyori et al. (2018). Figures 1 and 2 show the maps of the study area.

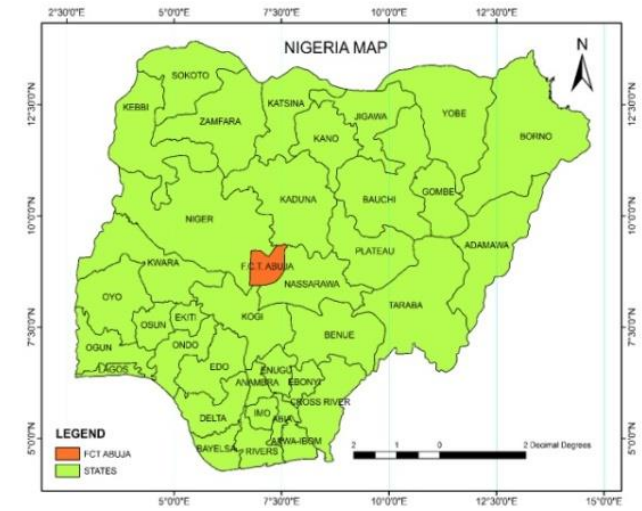

Figure 1: Map of Nigerian States and FCT Abuja Source: Arcinfo Shapefile 2010 (ESRI)

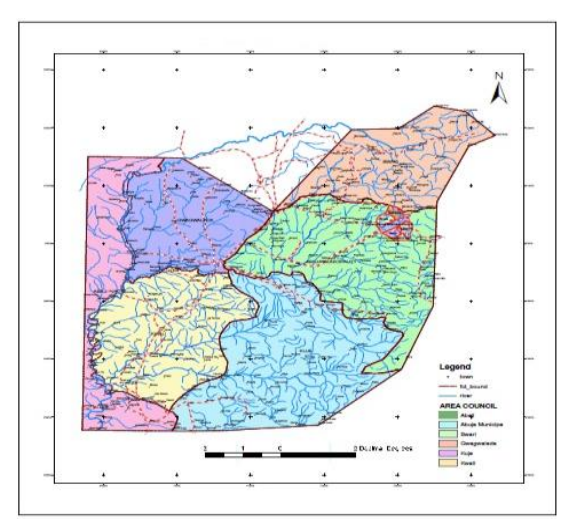

Figure 2: Map of FCT Six Area Councils Source: Survey and Mapping Dept., FCDA, Abuja

The scenarios considered in the study in Figure 2 are:

i. Lopsided location of controls within the whole FCT i.e. 24 controls as shown in figure 3

ii. Dense or closely located controls in the FCT i.e. 14 controls as shown in figure 4.

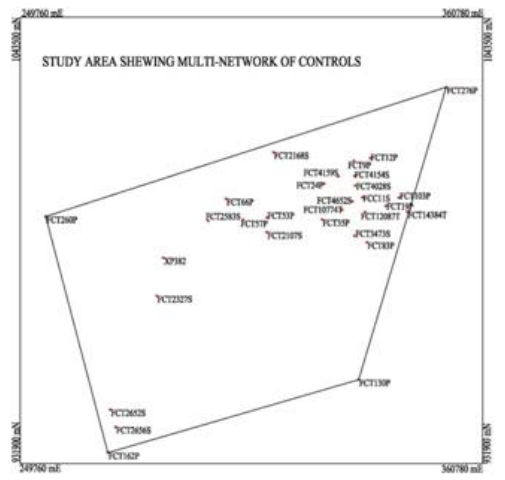

Figure 3: Plot of Lopsided Controls Within FCT.

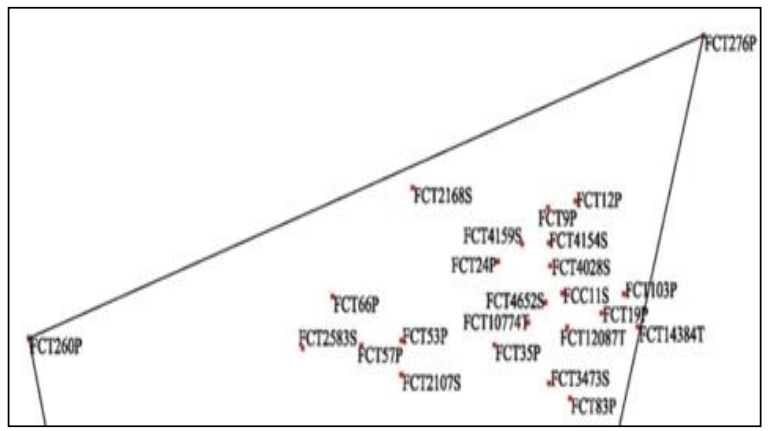

Figure 4: Plot of Densely Located Controls Within FCT.

\section{Geometric Geoid Models}

Geometric geoid model are determined by finding the differences between the ellipsoidal and orthometric heights of selected points to obtain the geoid heights of the points. A geometric geoid surface is then fitted to the computed geoid heights of the points to enable geoid heights of new points within the study area to be computed. Polynomial surfaces are used to represent continuous surfaces over study areas as stated by Oluyori et al. (2018). Oluyori et al. (2018) respectively gave the Multiquadratic and Bicubic models as:

$$
\begin{aligned}
& N=a_{0}+a_{1} X+a_{2} Y+a_{3} X^{2}+a_{4} Y^{2}+a_{5} X Y+a_{6} X^{2} Y+a_{7} X Y^{2}+a_{8} X^{2} Y^{2} \\
& N=a_{o}+a_{1} x+a_{2} y+a_{3} x^{2}+a_{4} y^{2}+a_{5} x y+a_{6} x^{2} y+a_{7} x y^{2}+a_{8} x^{3}+a_{9} y^{3}
\end{aligned}
$$

Where,

$$
\begin{aligned}
& Y=A B S\left(y-y_{o}\right) \\
& X=A B S\left(x-x_{o}\right)
\end{aligned}
$$




$$
\begin{aligned}
& y=\text { Northing coordinate of observed station } \\
& x=\text { Easting coordinate of observed station } \\
& y_{o}=\text { Northing coordinate of the origin (average of the northing coordinates) } \\
& x_{o}=\text { Easting coordinate of the origin (average of the easting coordinates) } \\
& N \text { is geoidal undulation at the point of interest } \\
& a_{0}, a_{1}, a_{2}, \ldots, a_{n}, \text { unknown parameters }
\end{aligned}
$$

To enable redundancies for robustness of least squares solution, geoidal undulation $(N)$ of at least eleven points must be known within the study area.

\section{Geo-spatial Prediction Methods}

Geo-statistics was originally developed as a self-contained methodology for spatial prediction opined Matheron (1963). One of the fundamental premises in geo-statistics is the similarity in the values of the analyzed variable as a function of distance opined Cellmer (2014). Geo-statistical prediction includes two stages:

i. Identification and modelling of spatial structure where continuity, homogeneity and spatial structure of a given variable is studied using a variogram.

ii. Geo-statistical estimation using kriging technique which depends on the properties of the fitted variogram which affects all stages of the process.

Since not all points can be observed or visited physically on the ground, the need for prediction to obtain acceptable data/information is very important for decision making and analysis. One of the methods of prediction is by Kriging. Kriging was developed by Krige $(1951,1962)$ who pursued the moving average concept in statistical interpolation methods to remove the effect of regression in estimating mineral resources.

\section{METHODOLOGY}

The methodology adopted in this study was divided into data acquisition, data processing and results presentation and analysis. Figure 5 shows the flow chart of the adopted methodology.

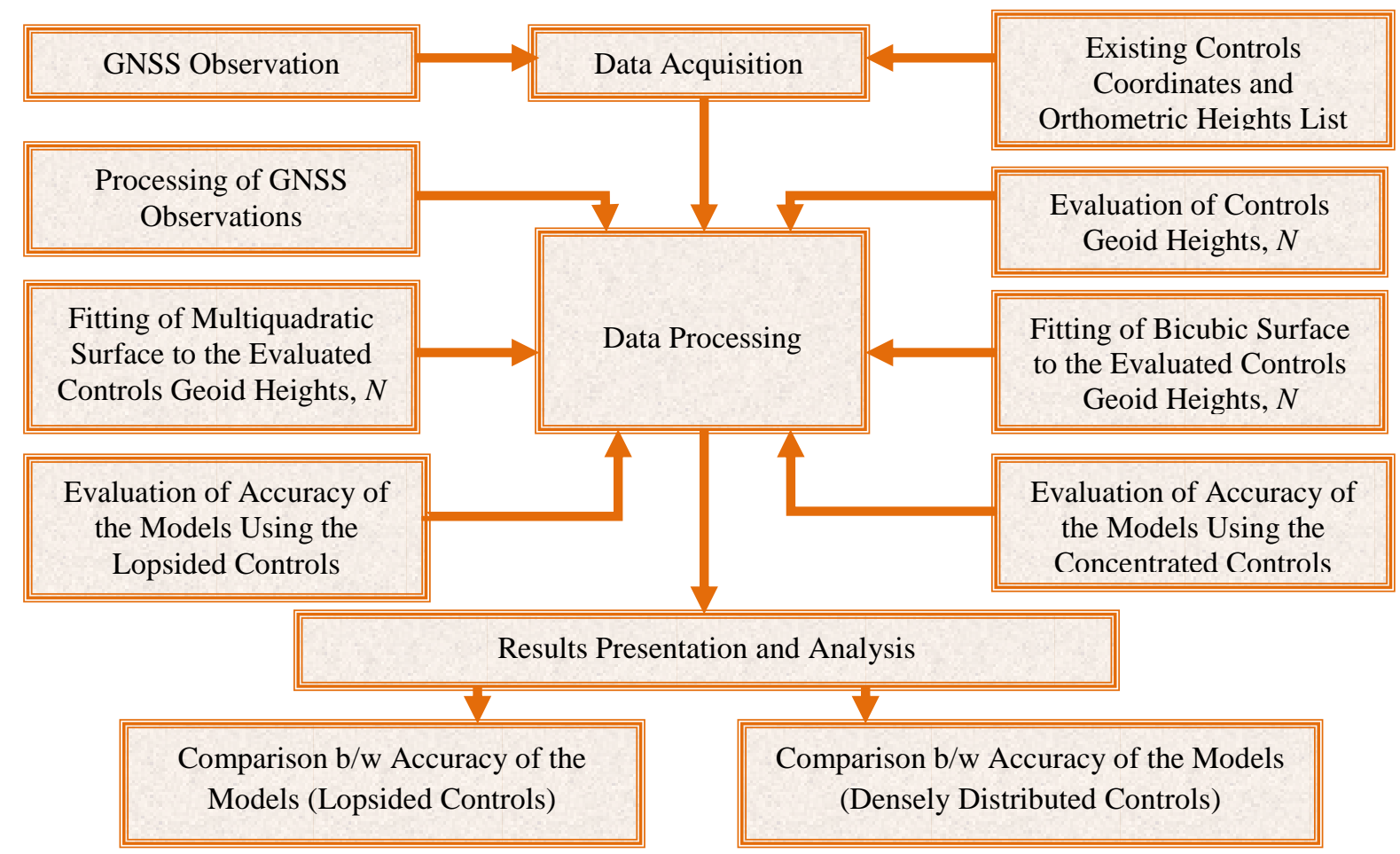

Figure 5: Adopted Methodology Flow Chart

DGPS receivers (dual frequency Hi-Target V30 Pro GNSS) were used to acquire data for two hours in static mode on controls (primary and secondary order) in FCT. The northing, easting and ellipsoidal heights, $h$ of the control points were obtained from the processing of the DGPS observations. The secondary data, northing, easting and orthometric heights, $H$ of the controls were obtained from the Surveying and Mapping Department of FCDA, Abuja. The geoid heights of the occupied points were computed 
using the ellipsoidal heights obtained from DGPS observation and the existing orthometric heights of the control stations with equation (1). The multi-quadratic and bicubic polynomial surfaces, equations (2) and (3) were fitted to the geoid heights of the controls to enable the geoid heights of new points within the study area to be computed using the determined geoid models. Microsoft Excel programs were written using equations (2) and (3). The orthometric heights of the points were computed from the two determined geometric geoid models, multiquadratic and bicubic models as given in table 1.

Table 1: Eastings, Northings and Models Orthometric $(\mathrm{H})$ heights

\begin{tabular}{|c|c|c|c|c|}
\hline Controls & Eastings(m) & Northings $(\mathbf{m})$ & H(m)Multiquadratic & H(m) Bicubic \\
\hline FCC11S & 331888.114 & 998442.043 & 485.161 & 485.149 \\
\hline FCT260P & 255881.175 & 993666.807 & 201.963 & 201.956 \\
\hline FCT103P & 340639.766 & 998375.578 & 532.681 & 532.710 \\
\hline FCT12P & 333743.992 & 1008308.730 & 735.826 & 735.913 \\
\hline FCT19P & 337452.408 & 996344.691 & 635.703 & 635.704 \\
\hline FCT2168S & 308926.908 & 989748.256 & 431.087 & 431.097 \\
\hline FCT24P & 310554.927 & 1009739.930 & 453.807 & 453.684 \\
\hline FCT276P & 322719.776 & 1001884.850 & 625.58 & 625.506 \\
\hline FCT4154S & 351983.716 & 1025998.314 & 476.896 & 476.911 \\
\hline FCT4159S & 329953.882 & 1003831.280 & 452.269 & 452.228 \\
\hline FCT66P & 326124.422 & 1003742.860 & 296.925 & 296.858 \\
\hline FCT9P & 299148.035 & 998114.283 & 497.334 & 497.394 \\
\hline FCT35P & 329821.512 & 1007612.091 & 427.252 & 427.276 \\
\hline FCT57P & 322183.380 & 992926.363 & 323.747 & 323.768 \\
\hline FCT4028S & 303234.270 & 992916.402 & 449.642 & 449.635 \\
\hline FCT53P & 330164.634 & 1001388.240 & 351.944 & 352.011 \\
\hline FCT4652S & 308943.361 & 993406.773 & 462.916 & 462.876 \\
\hline FCT162P & 329441.767 & 997474.808 & 189.694 & 189.789 \\
\hline FCT130P & 270791.291 & 934625.533 & 695.579 & 695.596 \\
\hline FCT2327S & 330982.584 & 952889.869 & 183.221 & 183.283 \\
\hline FCT2652S & 282526.612 & 973821.470 & 138.960 & 139.091 \\
\hline FCT2656S & 271370.273 & 945385.429 & 204.715 & 204.503 \\
\hline FCT83P & 272644.591 & 941062.460 & 568.910 & 568.872 \\
\hline XP382 & 332954.205 & 987231.606 & 274.399 & 274.401 \\
\hline
\end{tabular}

The two geometric geoid models (Multiquadratic and Bicubic models) orthometric heights were compared with their respective known orthometric heights to obtain the standard errors as well as the accuracy of each of the determined models considering both lopsided and clustered located controls. In the lopsided located controls, all the control stations (24 controls) orthometric heights were considered while in the clustered located controls, only 14 control stations that were closely located orthometric heights were considered.

\section{RESULTS PRESENTATION AND ANALYSIS}

Table 2 and figure 6 present comparison between the accuracy of Multiquadratic and Bicubic models considering only the lopsided controls. This was done to determine which of these models is better in terms of accuracy for application in the study area. Standard deviation is one of the indicators of how the model fits the FCT surface. The smaller the Standard deviation, the better the geoid model. It can be seen from table 2 that the standard deviation $(\sigma)$ of multiquadratic and bicubic models are respectively $0.109959231 \mathrm{~m}$ and $0.135719119 \mathrm{~m}$. That is, $11 \mathrm{~cm}$ as against $14 \mathrm{~cm}$ accuracy which implies that multiquadratic model is better for application in the study area than bicubic model. It can also be seen from figure 6 that the bar of the multiquadratic model is smaller than that of the bicubic model, which also implies that the multiquadratic model is better for application in FCT than the bicubic model. Though the two models can be applied throughout the FCT as the difference between their standard errors is very small. 
Table 2: Comparison between the Accuracy of Multiquadratic and Bicubic Models (Lopsided Controls)

\begin{tabular}{|c|c|c|c|c|}
\hline Controls & $\begin{array}{l}\text { DIFF B/W EXISTING AND } \\
\text { MULTIQUADRATIC } \\
\text { MODEL ORTHOMETRIC } \\
\text { HEIGHTS (A) }\end{array}$ & $\begin{array}{l}\text { DIFF B/W EXISTING } \\
\text { AND BICUBIC MODEL } \\
\text { ORTHOMETRIC } \\
\text { HEIGHTS (B) }\end{array}$ & $\mathbf{A}^{2}$ & $\mathbf{B}^{2}$ \\
\hline FCC11S & 0.285841605 & 0.298482551 & 0.0817054233 & 0.0890918334 \\
\hline FCT260P & 0.019112060 & 0.012296746 & 0.0003652708 & 0.0001512100 \\
\hline FCT103P & 0.122675646 & 0.151970694 & 0.0150493142 & 0.0230950917 \\
\hline FCT12P & 0.119230612 & 0.205745694 & 0.0142159389 & 0.0423312904 \\
\hline FCT19P & 0.059281596 & 0.060457902 & 0.0035143076 & 0.0036551580 \\
\hline FCT2168S & 0.000472599 & 0.009592057 & 0.0000002233 & 0.0000920076 \\
\hline FCT24P & 0.002586221 & 0.119698876 & 0.0000066885 & 0.0143278209 \\
\hline FCT276P & 0.008313477 & 0.066451743 & 0.0000691139 & 0.0044158342 \\
\hline FCT4154S & 0.085268640 & 0.069715646 & 0.0072707410 & 0.0048602712 \\
\hline FCT4159S & 0.039248531 & 0.001560435 & 0.0015404472 & 0.0000024350 \\
\hline FCT66P & 0.185538642 & 0.252681189 & 0.0344245876 & 0.0638477831 \\
\hline FCT9P & 0.081473227 & 0.140784399 & 0.0066378867 & 0.0198202470 \\
\hline FCT35P & 0.080509242 & 0.105236756 & 0.0064817381 & 0.0110747748 \\
\hline FCT57P & 0.096904403 & 0.075769114 & 0.0093904633 & 0.0057409586 \\
\hline FCT4028S & 0.049988498 & 0.043316085 & 0.0024988499 & 0.0018762832 \\
\hline FCT53P & 0.000778872 & 0.068313577 & 0.0000006066 & 0.0046667448 \\
\hline FCT4652S & 0.204730669 & 0.165304325 & 0.0419146470 & 0.0273255200 \\
\hline FCT162P & 0.001755336 & 0.092805825 & 0.0000030812 & 0.0086129211 \\
\hline FCT130P & 0.028904350 & 0.011997291 & 0.0008354615 & 0.0001439350 \\
\hline FCT2327S & 0.066385996 & 0.003844076 & 0.0044071005 & 0.0000147769 \\
\hline FCT2652S & 0.007916644 & 0.139298723 & 0.0000626733 & 0.0194041341 \\
\hline FCT2656S & 0.009012951 & 0.221467692 & 0.0000812333 & 0.0490479387 \\
\hline FCT83P & 0.157723116 & 0.120082336 & 0.0248765813 & 0.0144197674 \\
\hline XP382 & 0.186634409 & 0.184536082 & 0.0348324025 & 0.0340535656 \\
\hline \multicolumn{3}{|c|}{ STANDARD DEVIATION $\sigma\left(\right.$ SQRT OF AVERAGE OF $A^{2}$ or $\left.B^{2}\right)=$} & $0.109959231 \mathrm{~m}$ & $0.135719119 m$ \\
\hline
\end{tabular}

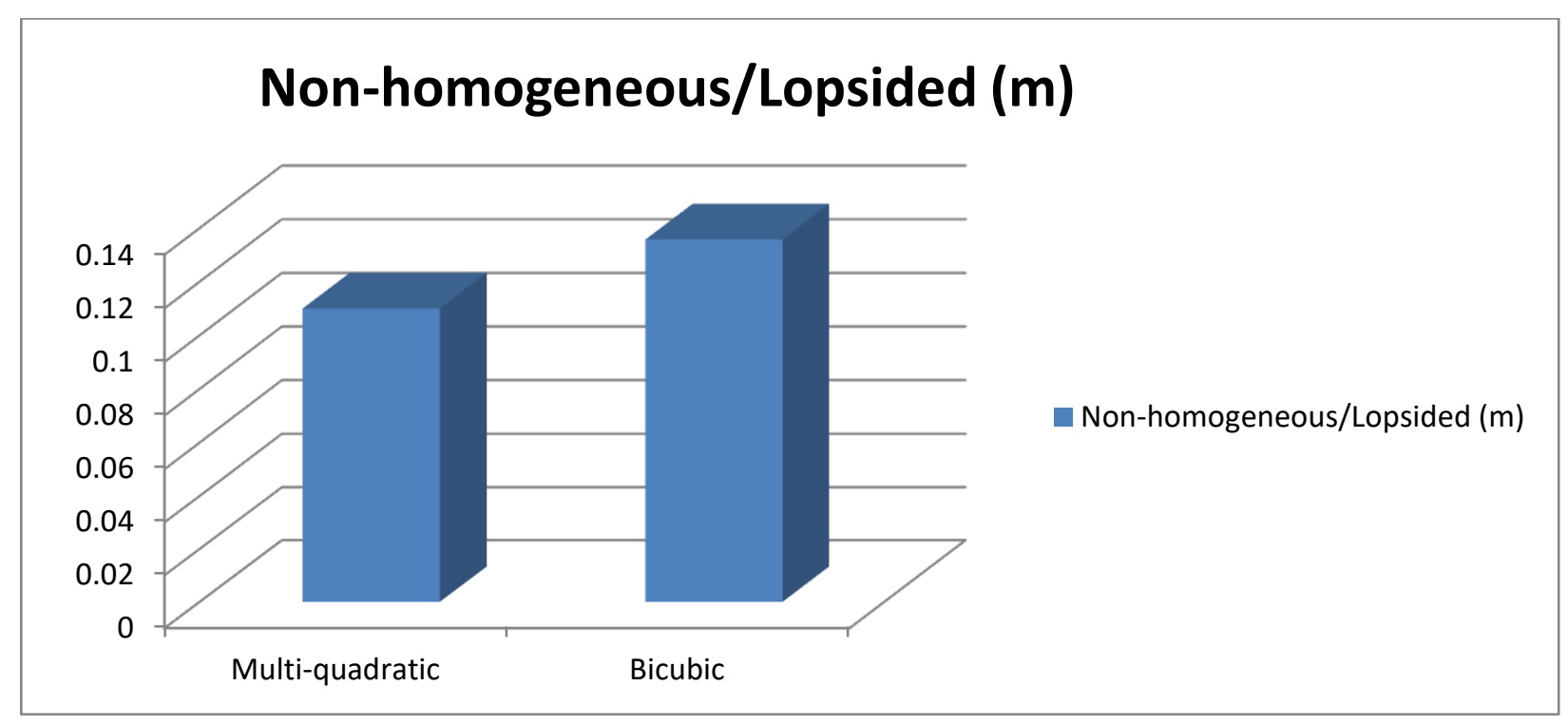

Figure 6: Plot of Standard Deviation of Multiquadratic and Bicubic Models Using the Non-homogeneous Controls

Also, tables 3 and 4, and figure 7 present the accuracy/standard deviation for multiquadratic and bicubic models using densely distributed points within the study area. This was done to compare the accuracy of the models using the total number of points (24 points) distributed within the entire study area and the densely distributed points (14 points) in a particular part of the study area. From table 3 it can be seen that the accuracy of the models, multiquadratic and bicubic are respectively $0.122391029 \mathrm{~m}$ and $0.153398946 \mathrm{~m}$. Comparing these accuracy of the models using tables 2,3 and 4 , and figure 7 , it can be seen that the accuracy of 
the models were better when the total number of points distributed within the entire study area was used than when a limited number of points within a particular part of the study area was used. This implies that the models can be applied across the entire study area with high accuracy/reliability irrespective of spatial distribution of the points.

Table 3: Accuracy of the Two Models (Multiquadratic and Bicubic Models) Using Densely Distributed Points in a Particular Part of the Study Area.

\begin{tabular}{|c|c|c|c|c|}
\hline $\begin{array}{c}\text { CONTROL } \\
\text { POINTS }\end{array}$ & $\begin{array}{c}\text { DIFF B/W EXISTING AND } \\
\text { MULTIQUADRATIC } \\
\text { MODEL ORTHOMETRIC } \\
\text { HEIGHTS (A) }\end{array}$ & $\begin{array}{c}\text { DIFF B/W } \\
\text { EXISTING AND } \\
\text { BICUBIC MODEL } \\
\text { ORTHOMETRIC } \\
\text { HEIGHTS (B) }\end{array}$ & A2 & B2 \\
\hline FCC11S & 0.285841605 & 0.298482551 & 0.081705423 & 0.089091833 \\
\hline FCT103P & 0.122675646 & 0.151970694 & 0.015049314 & 0.023095092 \\
\hline FCT12P & 0.119230612 & 0.205745694 & 0.014215939 & 0.042331290 \\
\hline FCT2168S & 0.000472599 & 0.009592057 & 0.000000223 & 0.000092008 \\
\hline FCT24P & 0.002586221 & 0.119698876 & 0.000006689 & 0.014327821 \\
\hline FCT66P & 0.185538642 & 0.252681189 & 0.034424588 & 0.063847783 \\
\hline FCT9P & 0.081473227 & 0.140784399 & 0.006637887 & 0.019820247 \\
\hline FCT35P & 0.080509242 & 0.105236756 & 0.006481738 & 0.011074775 \\
\hline FCT57P & 0.096904403 & 0.075769114 & 0.009390463 & 0.005740959 \\
\hline FCT4028S & 0.049988498 & 0.043316085 & 0.002498850 & 0.001876283 \\
\hline FCT53P & 0.000778872 & 0.068313577 & 0.000000607 & 0.004666745 \\
\hline FCT2327S & 0.066385996 & 0.003844076 & 0.004407101 & 0.000014777 \\
\hline FCT2652S & 0.007916644 & 0.139298723 & 0.000062673 & 0.019404134 \\
\hline XP382 & 0.186634409 & 0.184536082 & 0.034832403 & 0.034053566 \\
\hline STANDARD DEVIATION (SQRT OF AVERAGE OF A2 or B2) & $\mathbf{0 . 1 2 2 3 9 1 0 2 9}$ & $\mathbf{0 . 1 5 3 3 9 8 9 4 6}$ \\
\hline
\end{tabular}

Table 4: Lopsided and Dense Location Accuracy

\begin{tabular}{|c|c|c|}
\hline Model type & Non-homogeneous/Lopsided (m) & Concentrated/Dense (m) \\
\hline Multi-quadratic & 0.109959231 & 0.122391029 \\
\hline Bicubic & 0.135719119 & 0.153398946 \\
\hline
\end{tabular}

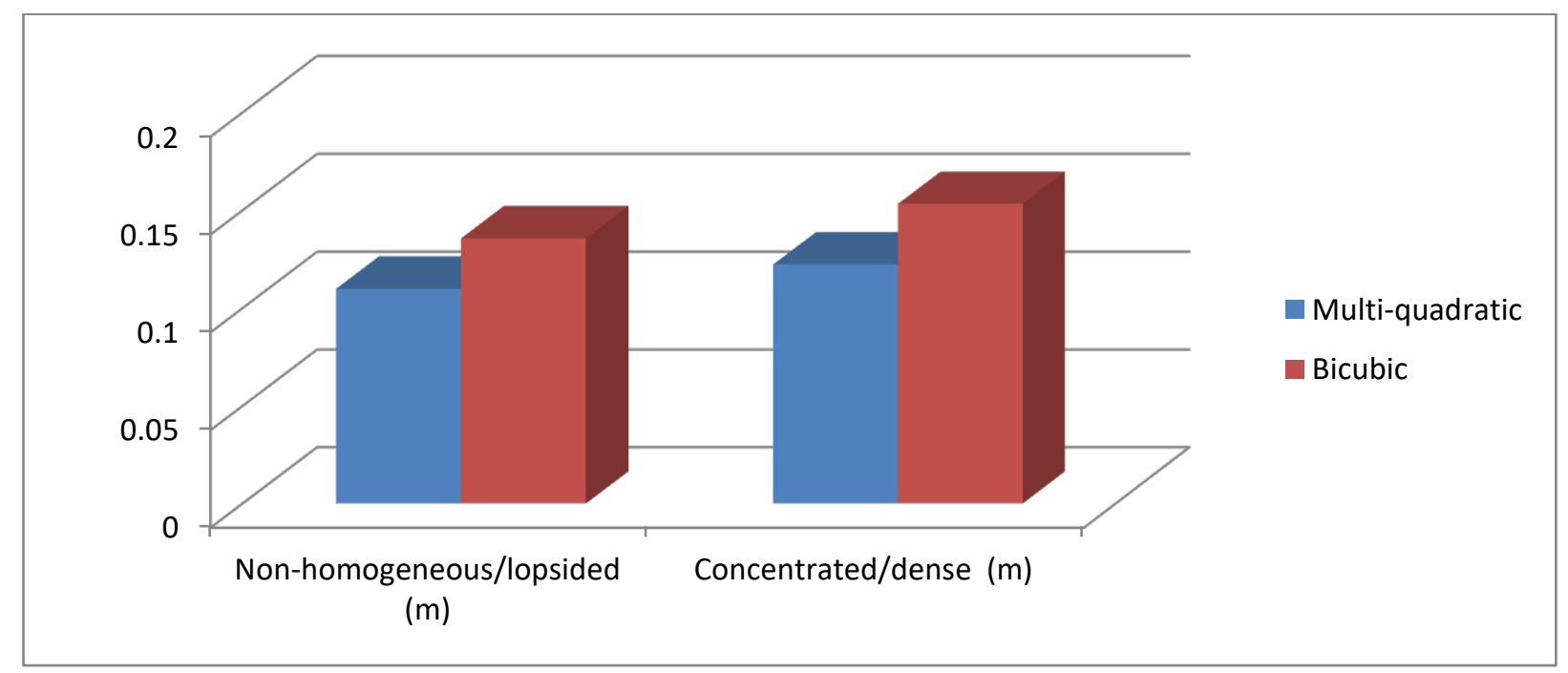

Figure 7: Plot of Standard Deviation of Multiquadratic and Bicubic Models Using Both Lopsided and Dense Controls 
The geographic location and size of a project area may point to the need for adoption of different polynomial interpolation surfaces used for different regions instead of single surface model to cover all. The ideal scenario is however, for a single geoid model to cover a study area which was achieved by Oluyori (2019).

Where control points represent only concentrated part of study area, the resulting model may have significant errors, which will lead to high prediction errors.

\section{CONCLUSION AND RECOMMENDATIONS}

i. Multiquadratic model is confirmed to take good care of lack of non-homogeneous distribution of selected controls in geoid modelling observed Oluyori (2019), Doganalp and Sevi (2015) and as well has the capacity to generate reliable geometric geoid model.

ii It is apparent that the standard deviation, $11 \mathrm{~cm}$ obtained over the whole study area for multiquadratic model is better than that of the concentrated part $(12 \mathrm{~cm})$ of the study area.

iii. Thus multiquadratic model is very appropriate for non-homogeneous distributed controls encountered in this study for geoid modelling.

iv. Spatial integrity and consistency enhances reliability of data for various applications within the study area.

\section{REFERENCES}

Cellmer R., (2014). The Possibilities and Limitations of Geo-statistical Methods in Real Estate Market Analyses. Real Estate Management and Valuation, Vol. 22, No. 3, pp 54-62.

Doganalp, S. and Selvi, H. Z. (2015). Local Geoid Determination in Strip Area Projects by Using Polynomials, Least-Square Collocation and Radial Basis Functions. Measurement, Vol. 73, pp 429-438. DOI: 10.1016/J.

Erol, B and Celik, R. H. (2004). TS7.3 Precise Local Geoid Determination to Make GPS Technique More Effective in Practical Application of Geodesy, FIG Working Week, Athens, Greece, May 22-27.

Eteje, S. O., Oduyebo, O. F. and Olulade, S. A. (2018). Procedure for the Determination of Local Gravimetric-Geometric Geoid Model. International Journal of Advances in Scientific Research and Engineering (IJASRE), Vol. 4, No. 8, pp $206-214$. DOI: http://doi.org/10.31695/IJASRE.2018.32858.

Eteje, S. O., Ono, M. N. and Oduyebo, O. F. (2019). Practical Local Geoid Model Determination for Mean Sea Level Heights of Surveys and Stable Building Projects. IOSR Journal of Environmental Science, Toxicology and Food Technology (IOSRJESTFT), Vol. 12, No. 6, pp 30-37. DOI: 10.9790/2402-1206013037.

Hansar, R (2016). Florida Permanent Network Reference, Geoid and View Datum, Design Training Expo.

Kaloop, M., Rabah, M. and EL-Shmbaky, H. (2008). High Accurate Local Geoid in Egypt. FIG Working Week, Stockholm, Sweden 14-19 June.

Krige, D. G., (1951). A Statistical Approach to Some Mine Valuations. Problems on the Witwatersrand. Journal of the Chemical Metallurgical and Mining Society of South Africa, December 1951, pp. 119-139.

Krige, D. G., (1962). Statistical Applications in Mine Valuation. J. Inst. Mine Survey South Africa, Vol. 12, No. 2, pp. 95-136. John Wiley \& Sons Ltd, The Atrium, Southern Gate, Chichester. 006).

Longley, P., Goodchild, M., Maguire, D., Rhind, D. (2005). Geographic Information Systems and Science. John Wiley \& Sons Ltd, the Atrium, Southern Gate, Chichester.

Matheron, G. (1963). Principles of Geo-statistics. Economic Geology, Vol. 58, pp 1246-1266.

Ning, Fang-Shii (2015). Using Surface and Buffer Analysis to Estimate Regional Geoid Undulation. Geoid, Vol.21.No. 3.

Nwilo, P. C. (2013). Technological Advancement in Surveying and Mapping: The Nigerian Adaptation. FIG Working Week, Abuja Nigeria 2013.

Oluyori, P. D. (2019). Modeling of Orthometric Heights from Multi-Networks of GNSS/Precise Levelling in Federal Capital Territory, Abuja, Nigeria. Unpublished Ph.D Dissertation of the Department of Surveying and Geoinformatics, Nnamdi Azikiwe University, Awka, Anambra State.

Oluyori, P. D., Ono, M. N. and Eteje, S. O. (2018). Comparison of Two Polynomial Geoid Models of GNSS/Levelling Geoid Development for Orthometric Heights in FCT, Abuja. International Journal of Engineering Research and Advanced Technology (IJERAT), Vol. 4, No. 10, pp 1-9. DOI: http://doi.org/10.31695/IJERAT.2018.3330.

Oluyori, P. D., Ono, M. N. and Eteje, S. O. (2018). Computations of Geoid Undulation from Comparison of GNSS/Levelling with EGM 2008 for Geodetic Applications. International Journal of Scientific and Research Publications, Vol. 8, No. 10, pp 235-241. DOI: 10.29322/IJSRP.8.10.2018.p8230. 